\title{
Annoying Pain
}

National Cancer Institute

\section{Source}

National Cancer Institute. Annoying Pain. NCI Thesaurus. Code C101162.

A sensation of discomfort or distress that is bothersome and irritating. 